\title{
Generation of TALEN-mediated FH knockout rat model
}

Research Paper

\author{
Dandan Yu ${ }^{1,9,10}$, Yali Zhong ${ }^{1}$, Xiaoran Li ${ }^{9,10}$, Yaqing Li ${ }^{1}$, Xiaoli Li ${ }^{1}$, Jing Cao ${ }^{1,2}$, Zhirui \\ Fan $^{1}$, Huijie Fan ${ }^{1}$, Long Yuan ${ }^{3}$, Benling Xu ${ }^{4}$, Yuan Yuan ${ }^{5}$, Hongquan Zhang ${ }^{6}$, Zhenyu Ji ${ }^{7}$, \\ Jian-Guo Wen ${ }^{8}$, Mingzhi Zhang ${ }^{1}$, Jahn M. Nesland ${ }^{9,10}$, Zhenhe Suo ${ }^{1,9,10}$ \\ ${ }^{1}$ Department of Oncology, The First Affiliated Hospital of Zhengzhou University, Zhengzhou, Henan, China \\ ${ }^{2}$ Departments of Pathology, The Third Affiliated Hospital of Zhengzhou University, Zhengzhou, Henan, China \\ ${ }^{3}$ Department of Surgery, The Affiliated Cancer Hospital of Zhengzhou University, Zhengzhou, Henan, China \\ ${ }^{4}$ Department of Cancer Biotherapy, The Affiliated Cancer Hospital of Zhengzhou University, Zhengzhou, Henan, China \\ ${ }^{5}$ Department of Pathology, Capital Medical University, Beijing, Fengtai, China \\ ${ }^{6}$ Department of Anatomy, Histology and Embryology, Peking University Health Science Center, Beijing, Fengtai, China \\ ${ }^{7}$ Department of Oncology, Henan Academy of Medical and Pharmaceutical Sciences, Zhengzhou University, Zhengzhou, \\ Henan, China \\ ${ }^{8}$ Institute of Clinical Medicine, The First Affiliated Hospital of Zhengzhou University, Zhengzhou University, Zhengzhou, \\ Henan, China \\ ${ }^{9}$ Department of Pathology, The Norwegian Radium Hospital, Oslo University Hospital, Oslo, Norway \\ ${ }^{10}$ Department of Pathology, Institute of Clinical Medicine, Faculty of Medicine, University of Oslo, Oslo, Norway
}

Correspondence to: Zhenhe Suo, email: zhenhes@medisin.uio.no

Keywords: TALEN, fumarate hydratase, gene technology, obesity, heterozygote

Received: February 23, $2016 \quad$ Accepted: August 09, $2016 \quad$ Published: August 19, 2016

\section{ABSTRACT}

Transcription activator-like effector nucleases (TALENs) are valuable tools for precise genome engineering of laboratory animals. Here we utilized this technique for efficient site-specific gene modification to create a fumarate hydratase (FH) gene knockout rat model, in which there was an 11 base-pair deletion in the first exon of the FH gene in 111 rats. 18 live-born targeted mutation offsprings were produced from 80 injected zygotes with $\mathbf{2 2 . 5 \%}$ efficiency, indicating high TALEN knockout success in rat zygots. Only heterozygous deletion was observed in the offsprings. Sixteen pairs of heterozygous FH knockout ( $\mathrm{FH}+/-$ ) rats were arranged for mating experiments for six months without any homozygous KO rat identified. Sequencing from the pregnant rats embryo samples showed no homozygous FH KO, indicating that homozygous FH $K O$ is embryonically lethal. Comparatively, the litter size was decreased in both male and female $\mathrm{FH}+/-\mathrm{KO}$ rats. There was no behaviour difference between the $\mathrm{FH}+/-\mathrm{KO}$ and the control rats except that the $\mathrm{FH}+/-\mathrm{KO}$ male rats showed significantly higher body weight in the 16-week observation period. Clinical haematology and biochemical examinations showed hematopoietic and kidney dysfunction in the $\mathrm{FH}+/-\mathrm{KO}$ rats. Small foci of anaplastic lesions of tubular epithelial cells around glomeruli were identified in the FH+/- kidney, and these anaplastic cells were comparatively positive for Ki67, p53 and Sox9, and such findings are most probably related to the kidney dysfunction reflected by the biochemical examinations of the rats. In conclusion, we have successfully established an $\mathrm{FH}+/-\mathrm{KO}$ rat model, which will be useful for further functional FH studies.

\section{INTRODUCTION}

Recently, with the development of genetic engineering technology, rapidly increasing researches focus on gene edited rats as an optimal model for human disease studies, including cancer, because rats are physiologically more similar to human than mice [1-3]. However, because of the high cost and technical demanding, production of genetically engineered rats has been severely hampered. Fortunately, several promising novel methods of efficient, 
targeted genome editing technology have emerged, including zinc finger nucleases (ZFN) [4], transcription activator-like effector nucleases (TALENs) [5] and the recently developed clustered regularly interspaced short palindromic repeat (CRISPR) [6] , all useful to efficiently modify the genome DNA sequence. TALENs are customizable, DNA binding nucleases that can be targeted to bind almost any sequence in the genome. Every TALEN is consisted of two domains, one is composed by repeating units to form DNA binding domain, and the other is FoK I endonuclease, which has the unspecificity activity of endonuclease. Each repeating unit is composed by 33-35 amino acids, and the adjacent amino acids of 12 and 13 can specifically recognize DNA nucleotide sequences, such as the amino acids of NI, NN, NG, HD can identification A, G, T, C bases, respectively. Therefore, TALEN can edit the genome with higher accuracy and specificity, which can be easily designed, cloned, assembled and tested in a molecular biology laboratory.

In this study, we utilized the TALENs for efficient site-specific gene modification to create a novel genefumarate hydratase $(\mathrm{FH})$ knockout $(\mathrm{KO})$ rat model. FH plays an important role in the Krebs tricarboxylic acid (TCA) cycle, which catalyses the hydration of fumarate into malate. Heterozygous mutations of $\mathrm{FH}$ are responsible for atypical uterine leiomyomas [7], hereditary leiomyomatosis [8] and renal cell cancer [7, 9]. Moreover, it was shown that FH deficiency could lead to metabolic disorder with severe encephalopathy, seizures, and poor neurological outcomes [10]. Dysfunctional FH in cells and tissues attributes to accumulating high levels of fumarate, which has been proposed to promote cancer development, indicating a tumor suppressor of $\mathrm{FH}$ [7]. The purposes of our current study are to explore whether germ-line FH KO rats could be generated and to know the general influence of the FH KO in the rat model.

\section{RESULTS}

\section{TALEN design and assembly}

TALEN plasmids targeting $\mathrm{FH}$ gene by using the Golden gate method were constructed and illustrated graphically in Figure 1A and 1B. All TALENs targeted the rat $\mathrm{FH}$ gene, in which the repeat unit of TAL specifically binds the DNA sequences and the pair of Fok I endonuclease precisely knockouts the FH sequences. Four pairs of TALEN plasmids targeting on the exon 1 of $\mathrm{FH}$ gene are shown in Table 1. The most effective plasmid was screened, showing that the FH-T3 has the most effective activity (Figure 1C).

\section{TALEN efficiency and TALEN-targeted product sequencing}

TALEN mRNAs were injected into the cytoplasm of 1-cell SD rat embryos in vitro and then the embryos were transferred to pseudopregnant recipients. In total, 18 liveborn targeted mutation offsprings were produced from 80 injected zygotes. The offsprings were then sequencingly screened for targeted disruption of FH exon 1 as illustrated in Figure 2B. The wild type (WT) sequence was found identical to that in the rat genome database (Figure 2A). Compared to the sequence in the WT rats, heterozygous rat founders were identified with 11 base deletions in one allele in exon 1. The mutation is a non-triple base deletion as shown in Figure 2C1, marked in red, and an early terminator "taa" was created in the exon 1 transcript as shown in Figure 2C2 marked in purple, which resulted in a very short transcript.

\section{Litter size observation and embryos sequencing}

To explore whether $\mathrm{FH}+/-$ influenced litter size, the following mating experiments were performed: female founder rats mated with WT SD males, and heterozygous offsprings mated with heterozygous offsprings. Interestingly, compared with the reproduction capability shown by WT/WT mating, the litter size was declined with $27.4 \%$ when heterozygous KO rats mated with WT rats, and declined with up to $40.0 \%$ when heterozygous $\mathrm{KO}$ rats mated to heterozygous $\mathrm{KO}$ rats as shown in Figure $3 \mathrm{~A}$. The litter size of the heterozygous $\mathrm{FH} \mathrm{KO}(\mathrm{FH}+/-)$ rat was increased in the heterozygous mating groups than in the heterozygous with WT mating groups, with a rate of $58.0 \%$, compared to the rate of $29.6 \%$. However, no homozygous FH KO rats were found in a total of 16 pairs of the heterozygous $\mathrm{KO}$ and heterozygous $\mathrm{KO}$ mating rats within the six month experiment. In order to further clarify embryo lethality of homozygous $\mathrm{FH} \mathrm{KO}$, embryos from E8.0 (Figure 3B) and E15.0 gestation rats (Figure 3C) were obtained. PCR products from these embryos were applied for DNA sequence analysis as illustrated in Figure 3D1 (WT) and Figure 3D2 (FH+/- ). Again, no homozygous FH KO rat was revealed in these embryos, indicating $\mathrm{FH}-/-\mathrm{KO}$ embryo lethality.

\section{$\mathrm{FH}+/-\mathrm{KO}$ resulted in reduced $\mathrm{FH}$ gene and protein expression}

To further analyze the $\mathrm{FH}+/-$ status in the rats, the expression of $\mathrm{FH}$ gene and protein was analyzed with RT-qPCR and Western blotting, respectively. Compared with the WT rats, the expression of FH gene was variably declined in the tissues of the heart, liver, lung, kidney, brain, spleen, stomach and testis as shown in Figure 4A, with a reduce rate of up to $67.2 \%$ in kidney $(P<0.001)$. Similarly, the expression of $\mathrm{FH}$ protein in the $\mathrm{FH}+/-\mathrm{KO}$ rats was also variably reduced in the tissues of the heart, liver, lung, kidney, brain, spleen, stomach and testis as shown in Figure 4B, and the histograms of the protein expression are shown on Figure $4 \mathrm{C}$, with a reduction rate of up to $16.3 \%$ in the kidney $(P<0.001)$. Expression of FH 
A TALEN construction $\mathbf{N}-\mathrm{C}$ DNA binding domain

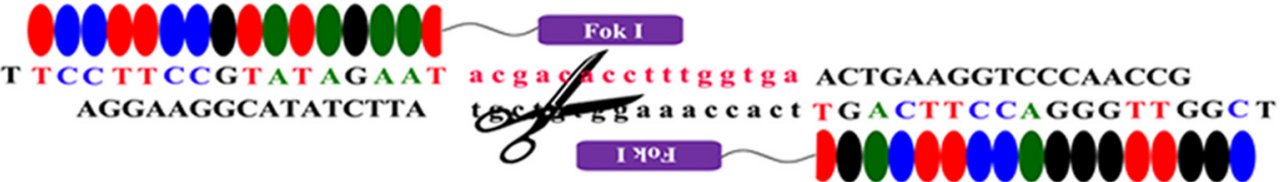

$N G=T \quad H D=C \quad N I=A \quad N N=G / A$

B

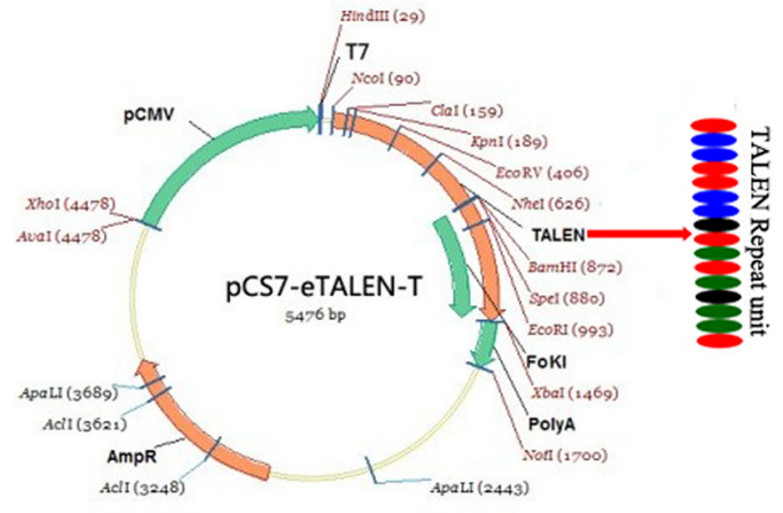

C

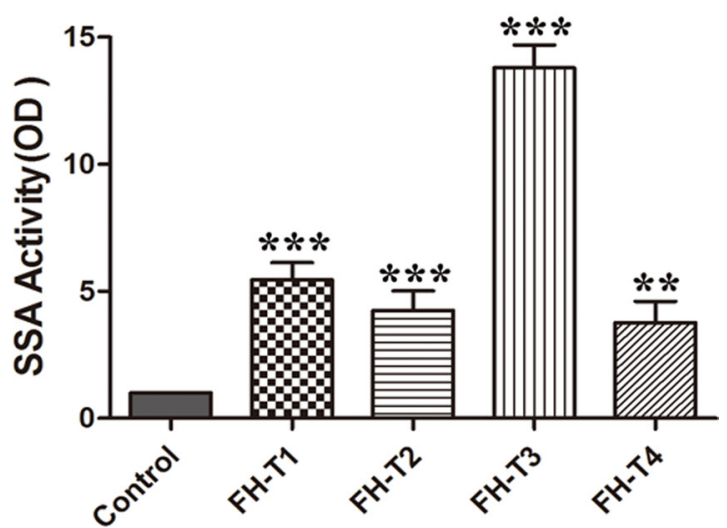

Figure 1: TALEN design and assembly. (A) shows the diagram of TALEN. (B) shows the assembly of TALEN. (C) shows the efficiency detect for the TALEN plasmids. The results shown that the FH-T3 has the most efficiency for knockout. $n=3$. $* P<0.05$, $* * P<0.01, * * * P<0.001$.

A

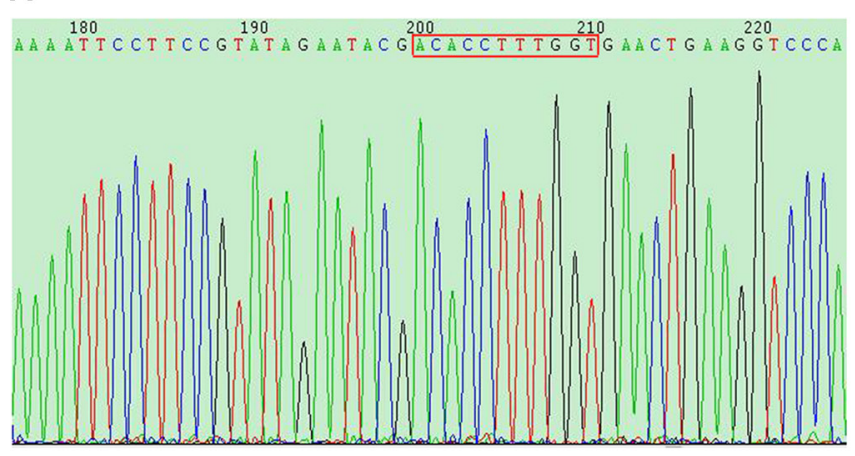

C $_{\mathrm{C} 1}$
B

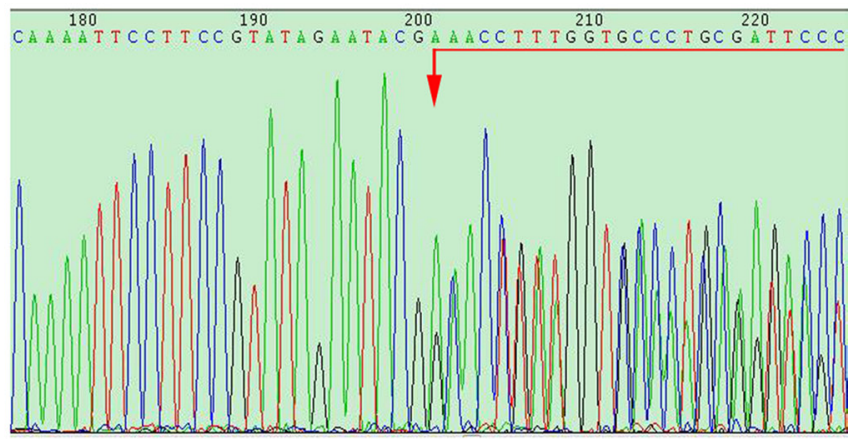

$\mathrm{C} 2$

1. atgaaccgegcattctgtctcctcgctcgctcgcgtcgettccegcgggtccectccgce

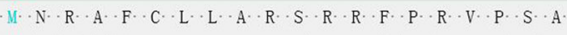
61. ggtgctgtattgtcaggggaagcggccaccctcccacggtgtgctccgaacgtcgtgcga

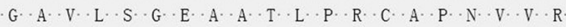

121 atggcaagccaaaat tccttccgtatagaatacggaactgaaggtcccaaccgataagta

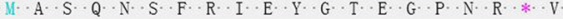

181- ttatggtgctcagact gtaagatctacgatgaactt taagattggaggtgcgacggagag

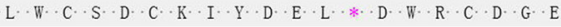

Figure 2: Rat tail DNA sequencing. (A) shows FH gene sequencing result of a WT rat, where the bases in the red rectangle are the TALEN targets. (B) shows FH sequencing result in a $\mathrm{FH}+/-\mathrm{KO}$ rat, on which, chaos sequencing waives begin from the first TALEN targeted base (arrow head). (C) sequencing results of the FH exon 1 cDNA in the WT and $\mathrm{FH}+/-\mathrm{KO}$ rats, where the red bases in $\mathrm{C} 1 \mathrm{shows}$ the TALEN targets in WT rat, and these bases are missing in the FH+/- KO rat on C2 with a terminator "taa" 20 bases after the TALEN targets, which results in a very short transcript. 
protein was also examined with an immunofluorescence microscope in the primary fibroblasts isolated from the $\mathrm{FH}+/-\mathrm{KO}$ rats and control rats. As shown in Figure 4D, cytoplasmic FH protein expression is detected in the fibroblasts of the control rat, but reduced immunostaining was revealed in the fibroblasts of the $\mathrm{FH}+/-\mathrm{KO}$ rat.

\section{Behaviour observation}

There was no behaviour difference between the WT and $\mathrm{FH}+/-\mathrm{KO}$ rats except the body weight. As shown in Figure $5 \mathrm{~A}$, the $\mathrm{FH}+/-$ male rats show significantly higher body weight within the 16-week observation period (Figure 5B), although the female $\mathrm{FH}+/-$ rats (Figure 5C) show no body weight difference within the same observation period. The maximum difference was observed at about 12-week in the $\mathrm{FH}+/-\mathrm{KO}$ males with up to $81.0 \%$ higher body weight $(P=0.012)$.

\section{Clinical haematology and biochemical examinations}

To explore whether $\mathrm{FH}+/-$ could influence haematological and biochemical molecule changes, a series of related blood samples were examined. All the measurements are shown in Table 4. As shown in
Figure 6A1, compared with the WT rats, the values of white blood cell (WBC), platelet hematocrit (PCT), $\%$ mononucleosis (\%MONO), \#lymphocyte (\#LYMPH) and \#eosimophil (\#EOS) in the $\mathrm{FH}+/-\mathrm{KO}$ rats were observed decreased with $49.0 \%(P=0.004), 14.7 \%$ $(P=0.039), 24.5 \%(P=0.025), 51.6 \%(P=0.007)$ and $58.0 \%(P=0.023)$, respectively, and the differences were consistent in both male (Figure 6A2) and female (Figure 6A3) rats. The lymphocytes of the $\mathrm{FH}+/-\mathrm{KO}$ rats were found morphologically immature (Figure 6B2), compared to the lymphocytes in the control rats (Figure 6B1). In addition, it was found that blood urea nitrogen (BUN) and creatinine (CRE) in the $\mathrm{FH}+/-\mathrm{KO}$ rats were increased with $20.1 \%(P=0.012)$ and $12.7 \%$ $(P=0.010)$, respectively, compared to the control rats (Figure 6C1). In addition, the blood UA was decreased in the $\mathrm{FH}+/-\mathrm{KO}$ rats as well, with about $25.0 \%$ reduction $(P=0.024)$, and this difference was consistent in both male (Figure 6C2) and female (Figure 6C3) rats, suggesting hematopoietic and kidney dysfunction in the $\mathrm{FH}+/-\mathrm{KO}$ rats.

\section{Histological and immunohistochemical evaluation}

Based on the abnormal findings of kidney function in the $\mathrm{FH}+/-\mathrm{KO}$ rats, histological and immunohistochemical
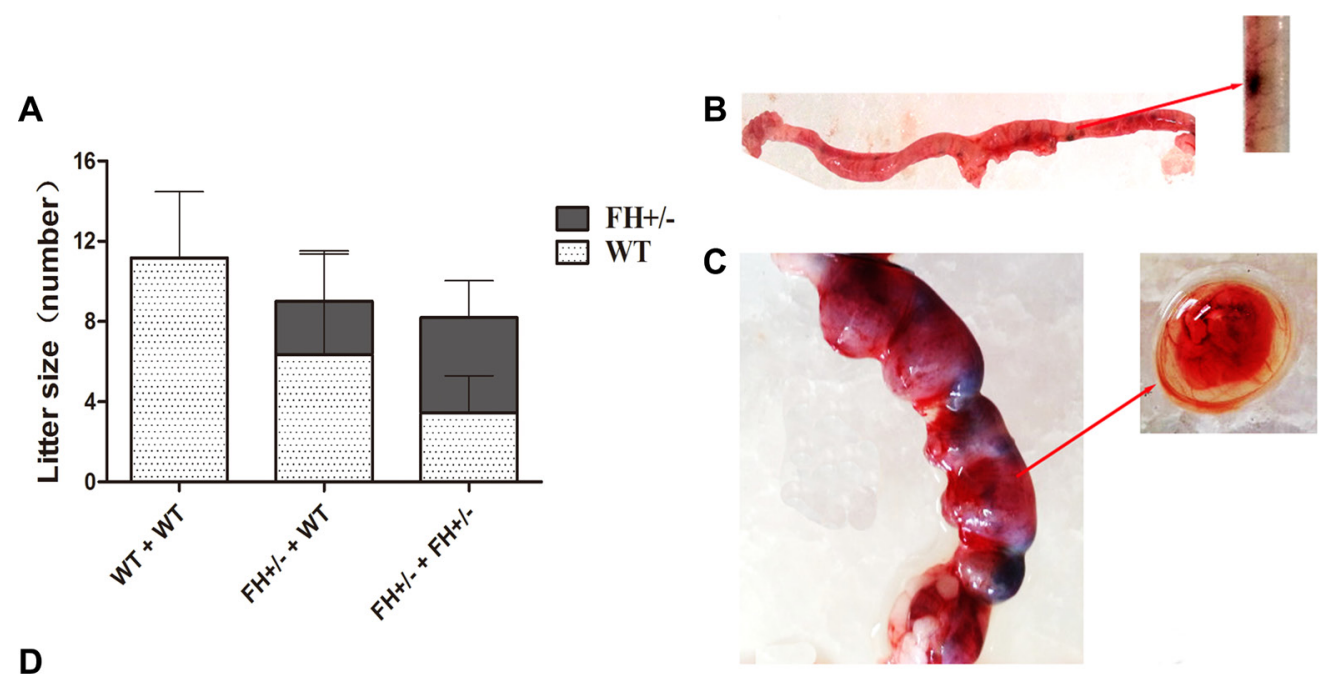

D

D2
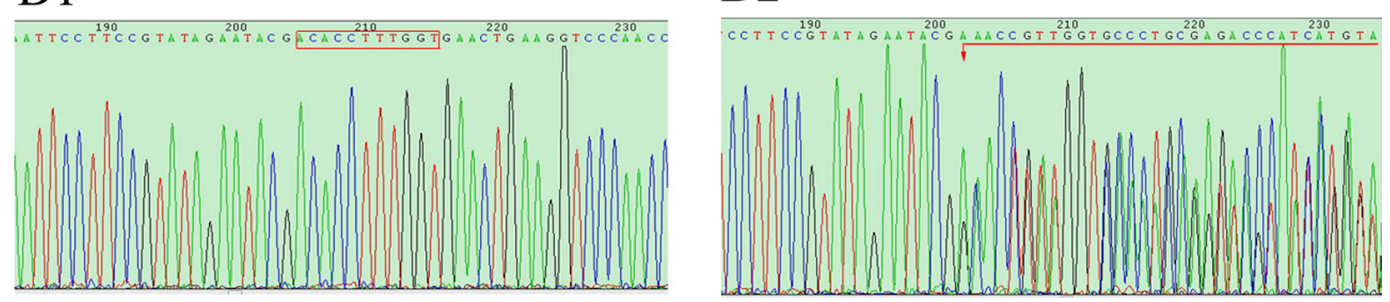

Figure 3: Litter size study and rat embryo sequencing. (A) shows the results of litter size observation in histograms. As shown on the histograms, the WT rat -WT rat mating groups show about 11 new born rats per litter, while the WT rat- FH+/-KO rat mating groups show 9 per litter with $29.6 \%$ decrease; and the $\mathrm{FH}+/-\mathrm{KO}$ rat-FH+/- KO rat mating groups show 8 per litter with $58.0 \%$ decrease. (B) shows embryos from an E8.0 rat. (C) shows embryos from an E15.0 rat. D1 and D2 show the results of FH sequencing in WT and FH+/- KO embryos, respectively. 
evaluation of the rat kidneys was further performed (Figure 7). Histologically, small foci in the medullary part of the kidney in the $\mathrm{FH}+/-\mathrm{KO}$ rats revealed anaplastic alterations with prominent pleomorphic larger nuclei and slightly coarse chromatin in the tubular epithelial cells around glomeruli. Those anaplastic larger epithelial cells were positive for Ki67, although the tubular epithelial cells in the same area in the control rats were largely negative or weakly positive. The same was for the p53 immunostaining. In the kidney tubular epithelial cells in the control rats, the p53 immunoreactivity was largely negative. However, areas of the kidney tubular epithelial cells in the same part in the $\mathrm{FH}+/-\mathrm{KO}$ rats were positive for the p53 expression. More prominent difference was seen in the Sox9 immunostained slides. While the kidney tubular epithelial cells in the control rats were negative or weakly positive, the kidney tubular epithelial cells in the same part in the $\mathrm{FH}+/-\mathrm{KO}$ rats were strongly positive for the Sox 9 expression.

\section{DISCUSSION}

To our knowledge, this is the first $\mathrm{FH}+/-\mathrm{KO}$ rat model established using the genome editing technology TALEN. We show on this report that the mutation results in a deletion of 11 bases in the first exon in one allele and due to the non-triple base deletion, an early terminator is created in the transcript, which generates the $\mathrm{FH}+/-$ rats. Although it is a heterozygous knockout, decreased mRNA and protein expression of the FH could be verified in both tissues and primary cells of the $\mathrm{FH}+/-\mathrm{KO}$ rats in our study. It is verified in our current study, although the new technology CRISPR/Cas9 is easier to use as indicated in literature [11-13], careful application of TALENs is still applicable in such studies. Furthermore, the established $\mathrm{FH}+/-\mathrm{KO}$ rat model will be useful for the studies of energy metabolism and the Warburg effect [14] as well.

Recently, the study of the FH has been a hot issue. It has been reported that the mutation of $\mathrm{FH}$ gene in the
A

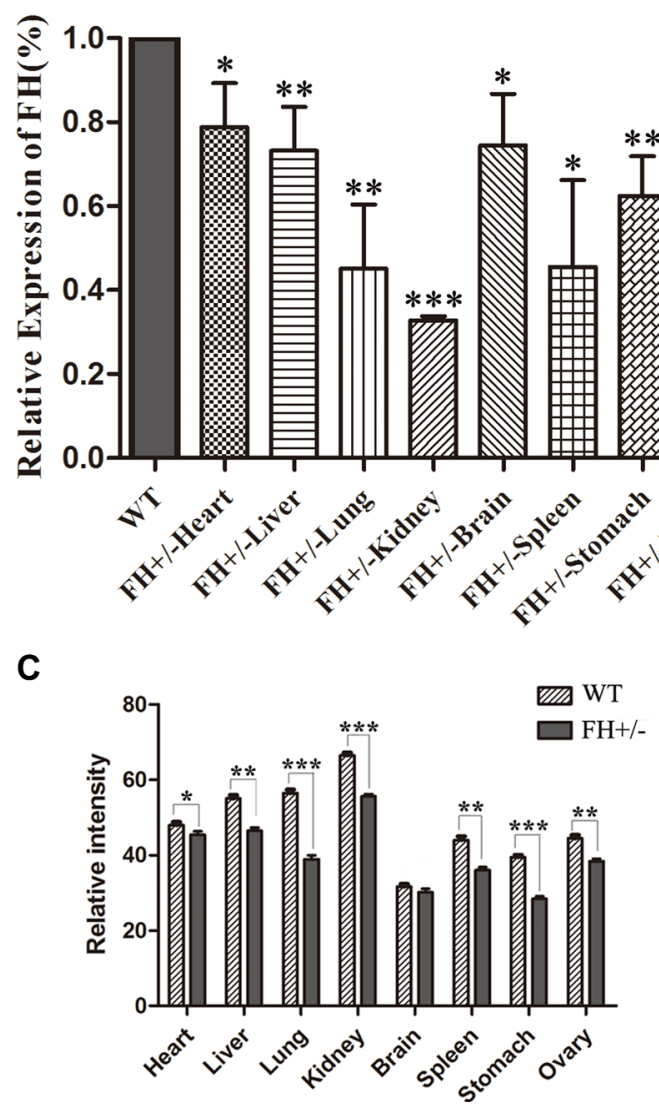

B

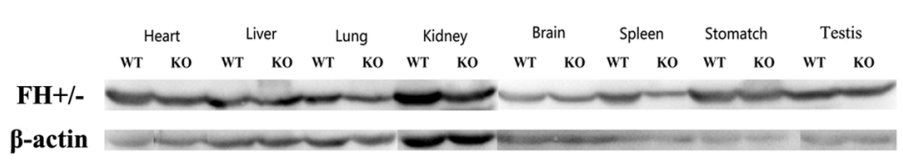

D

$\mathrm{FH}$

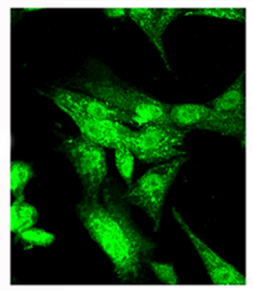

DAPI
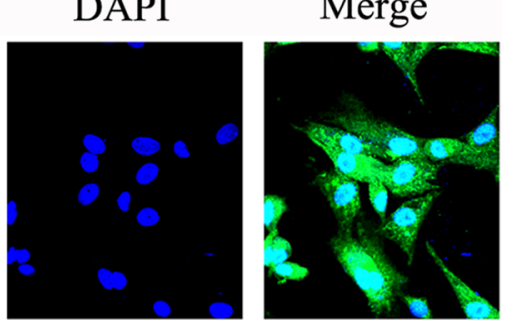

$\mathbf{F H + / -}$
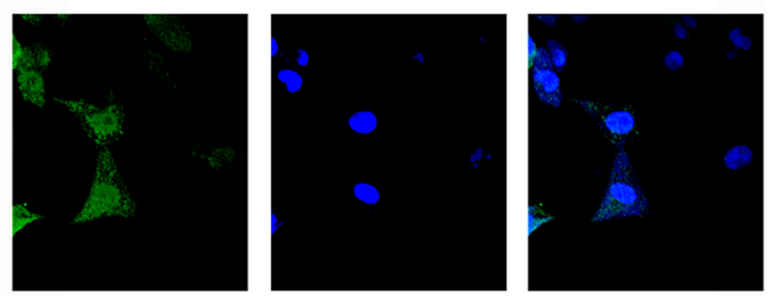

Figure 4: FH mRNA and protein expression examination. Results of the FH mRNA detected by RT-qPCR and protein expression examined with Western blotting in the heart, liver, lung, kidney, brain, spleen, stomach and testis tissues of WT and with FH+/- KO rats are shown on $(\mathbf{A})$ and $(\mathbf{B})$, respectively. $(\mathbf{C})$ shows the corresponding histograms of protein expression in the tissues from 3 WT rats and $3 \mathrm{FH}+/-\mathrm{KO}$ rats. Representative immunofluorescence microscopy of the FH protein in the primary lung fibroblast cells from WT and $\mathrm{FH}+/-\mathrm{KO}$ rats. Cells are stained with DAPI to visualize the nuclei (blue). FH (green) is localized in the cytoplasm. All photographs were originally taken at $200 \times(\mathbf{D})$. * means $P<0.05$, and ** means $P<0.01 . n=3$. 
NCCFH1 cell lines from a metastatic hereditary papillary renal cell carcinoma type 2 (PRCC2) results in glucosedependent growth and impaired oxidative phosphorylation, which is consistent with the Warburg effect [9]. A clinic study shows that the mutation of $\mathrm{FH}$ gene results in the Reed syndrome, which is an autosomal dominant disorder characterized by cutaneous leiomyomas, uterine leiomyomas [15], and renal cell carcinoma [7, 16, 17], possibly representing genetic heritage lesions [18]. In addition, FH deficiency also could lead to metabolic disorders with severe encephalopathy, seizures and poor neurological outcome [10], suggesting an important role of FH in neurology as well. It is known that absence of FH in cells leads to an accumulation of fumarate, which will activate hypoxia-inducible factors (HIFs) at normal oxygen tensions $[19,20]$. It is also known that mouse kidney cells, when their FH gene is knocked out, will survive with metabolic reprograming pathway beginning with glutamine uptake and ending with bilirubin [21]. FH-deficiency may activate the proto-oncogene ABL1 in kidney tumors, which may upregulate aerobic glycolysis via the mTOR/HIF1 $\alpha$ pathway, being a promising target marker [22].

In our study, we have generated an $\mathrm{FH}+/-\mathrm{KO}$ rat model with TALEN technology. 18 live-born targeted mutation offsprings were produced from 80 injected zygotes, with $22.5 \%$ efficiency, indicating a relatively high
TALEN knockout efficiency in rat zygotes. Interestingly, in an attempt to create $\mathrm{FH} \mathrm{KO}$ rat experiment with 16 pairs of $\mathrm{FH}+/-\mathrm{KO}$ rats, there were no homozygous $\mathrm{FH}$ $\mathrm{KO}$ rats observed within the six-month period for a total of four generations among the offsprings, strongly implying a possibility of embryo lethality of homozygous FH KO. Indeed, the sequencing of the E8.0 and the E15.0 gestation rat embryos did not reveal any homozygous FH mutation, which strongly support the embryo lethality discovered in the mouse study by Pollard PJ et al. [19], indicating the fundamental role of this gene in the development of life. The reason that we did not observe any homozygous embryo in our current experiments may be explained by the possibility of dead embryo absorption in the early embryo development as revealed in the mouse study [19].

Furthermore, we discovered reduced reproductive capability in the $\mathrm{FH}+/-\mathrm{KO}$ rats. Compared with the WT rats, the litter size was decreased when the WT rats were mated with the $\mathrm{FH}+/-\mathrm{KO}$ rats, and significantly reduced when $\mathrm{FH}+/-\mathrm{KO}$ rats were mated with $\mathrm{FH}+/-\mathrm{KO}$ rats, with about $40.0 \%$ reduction. Collectively, these results indicate reduced quality of sperm or ovum in the $\mathrm{FH}+/-$ $\mathrm{KO}$ rats, a scientific issue worthy of further study.

Interestingly, significantly higher body weight was disclosed in the $\mathrm{FH}+/-\mathrm{KO}$ male rats within the 16-week observation period, but the $\mathrm{FH}+/-\mathrm{KO}$ female
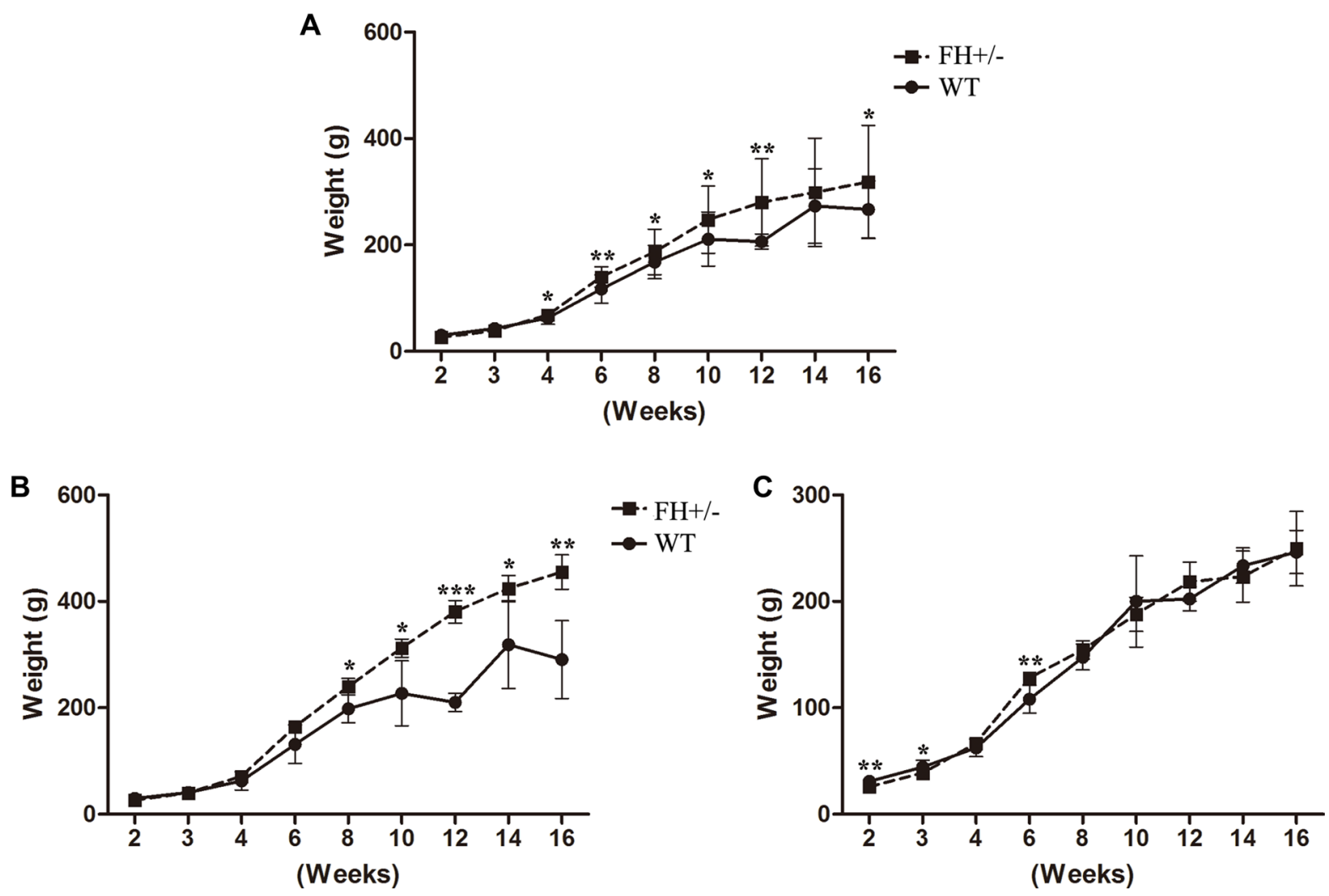

Figure 5: Body weight observation. (A), (B) and (C) show the general bodyweight curves for all the experimental rats, bodyweight curves for male rats and bodyweight curves for female rats, respectively. Compared to the WT rats, the male $\mathrm{FH}+/-\mathrm{KO}$ rats show significantly higher bodyweights. * means $P<0.05$, ** means $P<0.01$, ***means $P<0.001$. WT: $n=16$, male $=7$, female $=9$; FH+l-: $n=14$, male $=6$, female $=8$. 
rats did not show such a difference, a phenomenon meriting further studies. FH is a TCA cycle enzyme localized in the mitochondrial matrix, and the loss of $\mathrm{FH}$ enzyme activity will lead to disrupted TCA cycle, resulting in abnormal metabolism. This may be explained for the increasing bodyweight observed in the $\mathrm{FH}+/-\mathrm{KO}$ male rats, although the molecular mechanism behind this is still a matter of study. However, it is difficult to explain why the bodyweight in female $\mathrm{FH}+/-\mathrm{KO}$ rats is not similarly influenced. Apparently, the role of sex hormones in such a difference should not be excluded in the future study in terms of the bodyweight influence of the $\mathrm{FH}$ gene knockout.

Our clinical hematology and biochemistry analysis have shown reduced WBC, PCT, \%MONO, \#LYMPH, \#EOS and immature lymphocytes in the $\mathrm{FH}+/-\mathrm{KO}$ rats. All these decreased values refer to possibly abnormal hematopoietic function. In addition, there are increased values of CRE and BUN and decreased value of UA in the $\mathrm{FH}+/-\mathrm{KO}$ rats as well, an indication of kidney dysfunction as reported by Cakir $\mathrm{M}$ et al. [23]. Unfortunately, bone marrow materials from these rats were not available for further hematopoietic stem cell study.

FH is an essential enzyme of the TCA that catalyses the hydration of fumarate into malate. Abnormal FH function/expression impairs mitochondrial function directly and has indirect effects on both glucose metabolism and oxidative phosphorylation by inappropriate activation of HIF1 $\alpha$ and NRF2 [24, 25]. Recently, there are reports showing that the mutation of FH may initiate renal cell carcinogenesis $[7,9,18$, 26-29], implying tumor suppressor function of this gene. In our current study, we have histologically and immunohistochemically examined the kidney tissues. Histological evaluation of kidney samples does reveal foci of tubular epithelial cells around glomeruli in the
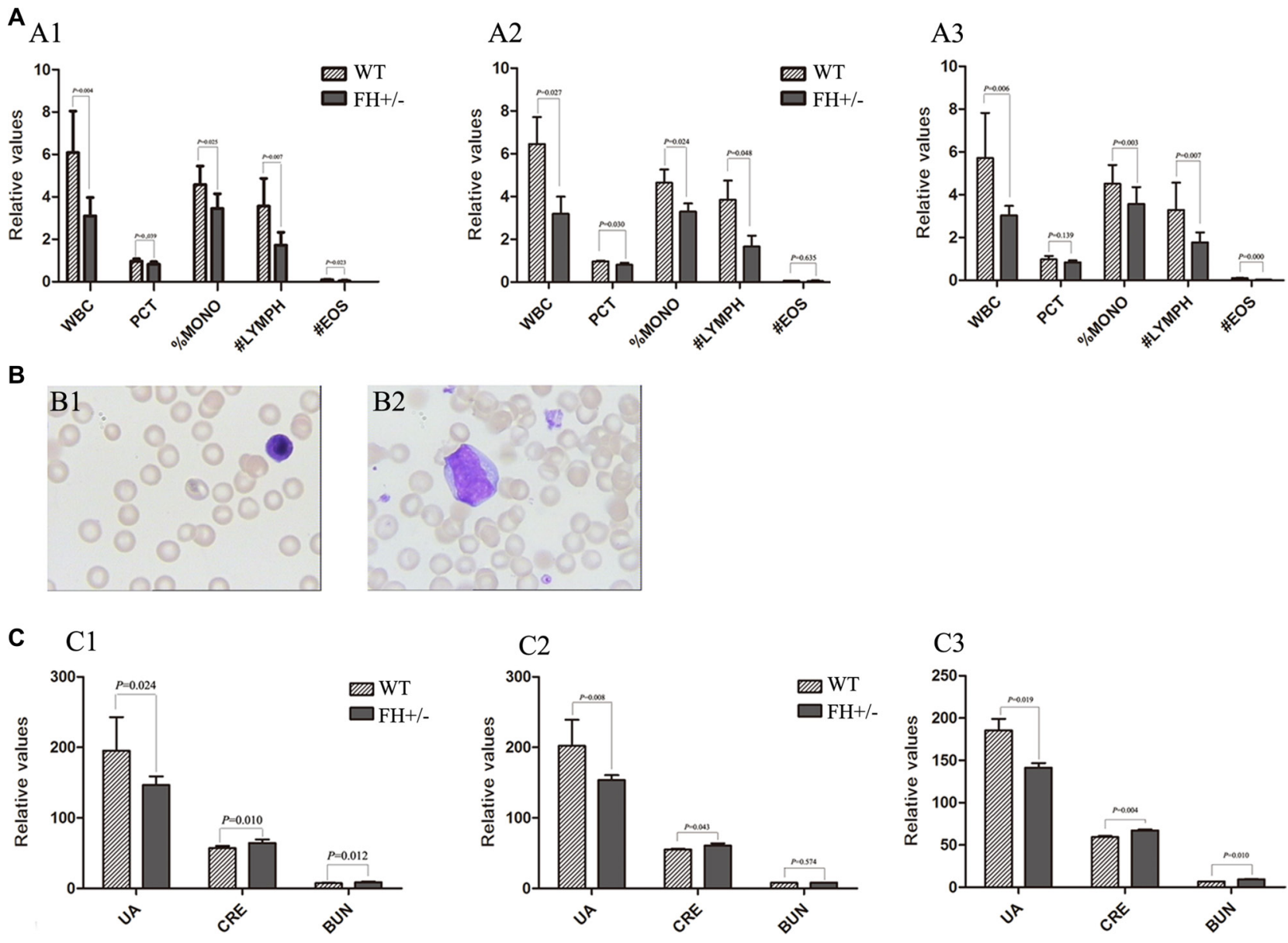

Figure 6: Results of haematology and biochemistry assays. (A) shows the histograms of the blood tests of WBC, PCT, \%MONO, \#LYMPH and \#EOS in the WT and FH+/- KO rats. The histograms of the blood tests in general, in the male and female rats are shown in $\mathrm{A} 1, \mathrm{~A} 2$ and A3, respectively, and all show significantly decreased values of $\mathrm{WBC}, \mathrm{PCT}, \% \mathrm{MONO}$, \#LYMPH and \#EOS in the FH+/- KO rats. Representative lymphocyte morphology photographs are shown in (B). While B1 shows mature small-size lymphocyte with rather larger cytoplasm in a WT rat, B2 shows a larger lymphocyte with bizzare giant nuclear in a FH+/- KO rat. (C) shows the results of blood biochemistry assays in histograms. $\mathrm{C} 1$ shows the results in general and $\mathrm{C} 2$ shows the results in the males while $\mathrm{C} 3$ shows the results in females. All results in the experimental rats are compared to the values in the WT rats. While the UA value is significantly decreased in the $\mathrm{FH}+/-\mathrm{KO}$ rats, the values of $\mathrm{CRE}$ and $\mathrm{BUN}$ in the $\mathrm{FH}+/-\mathrm{KO}$ rats are significantly increased. WBC: white blood cell; \%MONO: \%mononucleosis; \#LYMPH: \#lymphocyte; \#EOS: \#eosimophil; UA: uric acid; CRE: creatinine; BUN: blood urea nitrogen. 
$\mathrm{FH}+/-\mathrm{KO}$ rats with anaplastic alterations, and these cells express higher levels of Ki67, p53 and Sox9. These findings may explain the kidney dysfunction observed by the blood biochemical examinations. Although we did not observe tumor formation in the kidneys of the $\mathrm{FH}+$ $\mathrm{KO}$ rats, the anaplastic lesions in the medullary field of the kidney may indicate an early tumor development process, and this finding merits additional studies. Ki67 is a cellular proliferationmarker and its high expression is always associated proliferation activity of tumor cells [29]. p53 is a well-known tumor suppressor gene [30], and its high expression is often linked to p53 mutation, widely discovered in tumors. In addition, Sox 9 is defined as a specific cancer stemness biomarker [31]. All these findings highlight the possibility of premalignant lesions of the epitheleial cells around the glomeruli in the $\mathrm{FH}+/$ $\mathrm{KO}$ rats, although the p53 gene activity in these rats is current not clear.

In summary, we have successfully generated a TALEN-mediated $\mathrm{FH}+/-$ knockout rat model, and shown that homozygous FH knockout is embryonically lethal. The $\mathrm{FH}+/-\mathrm{KO}$ leads to reduced gene and protein expression of $\mathrm{FH}$ in both tissues and primary cells, and the $\mathrm{FH}+/-\mathrm{KO}$ rats show decreased litter size and increased body weight in male rats. In addition, the $\mathrm{FH}+/-\mathrm{KO}$ rats show variable hematopoietic and kidney dysfunction revealed by blood examinations. Collectively, our results indicate the potential value of this $\mathrm{FH}+/-\mathrm{KO}$ rat model in the studies of metabolic disorders and tumorigenesis in vivo.

\section{MATERIALS AND METHODS}

\section{Animals}

The study was approved by our Animal Research Committee (notion no. SYXK 2011-0001) and performed at the Laboratory of Experimental Animal Center of Henan Province in accordance with Institutional guidelines. Eight female and eight male Sprague-Dawley (SD) rats, initially average body weight of $220 \mathrm{~g}$, were used in this study, and all efforts were made to minimize distress. All the animals were kept in cages quilted with shavings and at a controlled temperature of $(24 \pm 2)^{\circ} \mathrm{C}$ under a $12 \mathrm{~h}$ light-

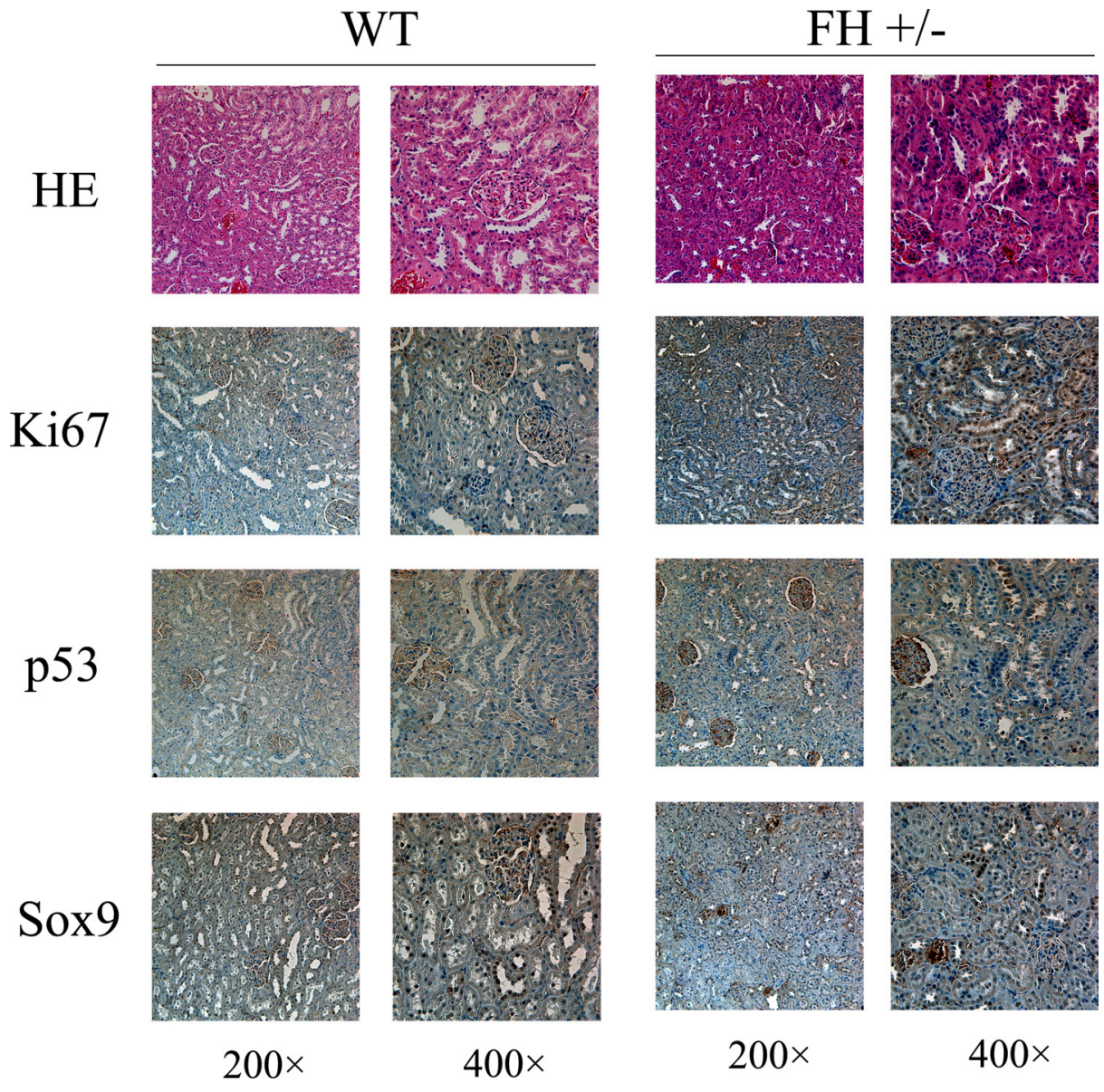

Figure 7: Histological and immunohistochemical results of rat kidney. Histological evaluation of the haematoxylin and eosin (HE) stained slides shows variable foci of tubular epithelial cells around glomeruli with abnormal structure and the cell nuclei are prominently bigger with thicker chromatin. These abnormal tubular epithelial cells in the $\mathrm{FH}+/-\mathrm{KO}$ rat kidney are more positive for the expression of Ki67, p53 and Sox9. 
dark cycle with free access to water and feed for 6 months. All animals received humane care in compliance with the ethical standards.

\section{TALEN construction}

A pair of TALENs targeting exon 1 of the $\mathrm{FH}$ gene was selected as a target by using a web-based tool called TAL Effector-Nucleotide Targeter ( https://tale-nt.cac. cornell.edu/) [32]. Fok I nuclease functions as a dimer when it plays a key role to make double-strand breaks (DSB) in the DNA sequences, especially the length of the spacer can significantly affect the specificity of the TALENs. Therefore the TALENs were designed in pairs to precisely bind opposing DNA target sequence, which were separated by the spacer, in order to search for the potential targets. The optimal length for the activity of TALEN should be between 14-20bp and the length of the repeat units should be 16-18bp. Moreover, the TALEN target sequence was chosen in such a principle that each target sequence started after a $\mathrm{T}$ base and ended with a $\mathrm{T}$ base, which is illustrated in Figure 1A. TALENs were assembled using the TALE Toolkit (Viewsolid biotech, China) according to the manufacturer's introduction. Final constructs were produced in the pCMV-T7-taleFokI-L/R backbone plasmid. Four pairs of TALEN plasmids were designed as shown in Figure 1B and the targeted sequences are shown in Table 1. TALEN mRNA was recovered by $\mathrm{LiC} 1$, washed and then resuspended in DEPC-treated H2O. The plasmids were extracted using E.Z.N.A ${ }^{\circledR}$ Plasmid Midi Kit (OMEGA, USA), according to the manufacturer $>$ s instructions. The most effective plasmid was screened by the Luciferase SSA kit (Viewsolid biotech, China). TALEN mRNA was stored at $-80{ }^{\circ} \mathrm{C}$ until used for embryo injection.

\section{Embryo microinjection}

Female embryo donors were superovlated with 25IU of pregnant mare serum gonadotropin (Millipore, USA), followed by $25 \mathrm{IU}$ of human chorionic gonadotropin (Millipore, USA) after $24 \mathrm{~h}$, then caged with a male rat individually. The following day, donors were sacrificed and embryos were collected from the oviducts and incubated in M16 (Millipore, USA) at $37^{\circ} \mathrm{C}$ in $5 \% \mathrm{CO}_{2}$ air. Fertilized one-cell embryos were transferred to medium for microinjection and the mRNAs of the pair of most effective TALEN plasmids were mixed and injected into the cytoplasm. Embryos that survived the injection procedure were surgically transferred to the oviduct of SD female rats.

\section{Mutation analysis}

Offsprings from injected embryos were obtained and verified for the mutations of FH gene. Briefly, the tail snips $(\sim 1 \mathrm{~cm})$ were cut from the 2-weeks age of offspring rats and the DNA were extracted by using the Tissue DNA Kit (OMEGA, USA) following the manufacturer's introduction. Then the extracted DNA was amplified by PCR, and the primers are shown in Table 2. The conditions for PCR analyses were as following: $98^{\circ} \mathrm{C} 3$ minutes; $98^{\circ} \mathrm{C} 10 \mathrm{~s}, 60^{\circ} \mathrm{C} 20 \mathrm{~s}, 72^{\circ} \mathrm{C} 20 \mathrm{~s}, 35$ cycles; $72^{\circ} \mathrm{C} 2$ minutes and $4^{\circ} \mathrm{C}$ preservation. Subsequently, the products of PCR were sent to a company (Sagon biotech, China) to verify the mutation.

\section{Biological behaviour analysis}

Offspring of the verified $\mathrm{FH}+/-\mathrm{KO}$ rats were mated with $\mathrm{FH}+/-\mathrm{KO}$ or with wild-type (WT) rats, and the birth rate was recorded, with the wild type male/female or female/male mating SD rats as control. Meantime, the clinical observation was recorded including body weight, fur coloration and life behaviour. The bodyweight of the paired $\mathrm{WT}$ and $\mathrm{FH}+/-\mathrm{KO} \mathrm{SD}$ rats that were born at the same time was examined every two weeks. In order to explore whether there were homozygous FH KO embryos, the pregnant potential $\mathrm{KO}$ female rats were sacrificed at E8.0 or E15.0, and the embryos were applied for DNA sequences as mentioned above.

\section{Primary cells extraction}

The experimental rats were euthanized with $10 \%$ chloral hydrate and the lungs were collected as soon as possible. The materials were placed in $\mathrm{PBS}$ at $4^{\circ} \mathrm{C}$, washed with new PBS and cut to tiny pieces before incubated with trypsin at $37^{\circ} \mathrm{C} 5$ minutes as reported $[33,34]$. Then tissue fragments inside the digestion solution were pipetted up and down to break the clumps and the supernatant solution was transferred to sterile $50 \mathrm{~mL}$ tubes containing warm DMEM/F12 media with 15\% FBS and $1 \mathrm{X}$ antibiotic/ antimycotic solution. The above procedures were repeated 8-10 times, and all the solution containing singular cells was collected and centrifuged for 5 minutes at 1,000 g. The cells were then placed into a $10 \mathrm{~cm}$ culture dish with $10 \mathrm{ml}$ warm DMEM/F12 media with $15 \%$ FBS, $1 \times$ antibiotic/antimycotic solution and incubated for $2 \mathrm{~h}$ at $37^{\circ} \mathrm{C}$ in $5 \% \mathrm{CO}_{2}$ before the medium was replaced with new one.

\section{Real-time quantitative polymerase chain reaction ( $R T-q P C R)$ Analysis}

Total RNAs were isolated from tissue samples of rats using the Trizol (Invitrogen, USA) with the glass homogenizer at room temperature (RT). RNA concentration was determined by spectrophotometric analysis (Eppendorf, Germany), and the integrity was tested by the OD260nm/OD280nm absorption ratio $(>1.7,<2.0)$. Reverse transcription reaction was applied 
Table 1: OGDH target sequences

\begin{tabular}{cll}
\hline Name & & \multicolumn{1}{c}{ Target Sequences $\mathbf{( \mathbf { 5 } ^ { \prime } \text { to } \mathbf { 3 } ^ { \prime } \mathbf { ) }}$} \\
\hline FH-T1 & Sense strand & F- TCGTTCCCGCGGGTC \\
& Antisense strand & R-AGCAAGGGCGCCCAG \\
FH-T2 & Sense strand & F- GGCCACCCTCCCACGGTGT \\
& Antisense strand & R-CCGGTGGGAGGGTGCCACA \\
FH-T3 & Sense strand & F- ACGACACCTTTGGTGA \\
& Antisense strand & R-TGCTGTGGAAACCACT \\
FH-T4 & Sense strand & F- CCAACCGATAAGTATT \\
& Antisense strand & R-GGTTGGCTATTCATAA \\
\hline
\end{tabular}

Table 2: Primers for sequencing

\begin{tabular}{ccc}
\hline gene name & \multicolumn{1}{c}{ sequence (5' to $\left.\mathbf{3}^{\prime}\right)$} \\
\hline FH & sense strand & F- CTGGGCAGTATGTGAATTGTATAAAC \\
& antisense strand & R- GAACCCTGACTAAAACAGCCC \\
\hline
\end{tabular}

Table 3: Primers for RT-qPCR

\begin{tabular}{cll}
\hline gene name & \multicolumn{1}{c}{ sequence (5' to $\left.\mathbf{3}^{\prime}\right)$} \\
\hline $\mathrm{FH}$ & sense strand & F-CTGGGCAGTATGTGAATTGTATAAAC \\
& antisense strand & R-GAACCCTGACTAAAACAGCCC \\
\hline
\end{tabular}

with $2 \mu \mathrm{g}$ of total RNA using the RevertAid First Strand cDNA Synthesis kit (Thermo Scientific, USA) according to the manufacturer's instruction. Amplification reaction was performed by using the MiniOpticon detection system (Bio-Rad, USA) with the SYBR Premix Ex Taq II (Takara, Japan). The primers are shown in Table 3 and all PCRs were performed in duplicate and the reaction conditions are as following: $30 \mathrm{~s}$ at $95^{\circ} \mathrm{C}, 40$ cycles of $5 \mathrm{~s}$ at $95^{\circ} \mathrm{C}$ and 30 s at $60^{\circ} \mathrm{C}$ (LightCycler480, Roche, USA). The results of FH mRNA expression levels were calculated by using the comparative cycle threshold (CT) and the relative changes in the FH level were analysed with the $2^{-\Delta \Delta \mathrm{CT}}$ formula.

\section{Western blotting}

After the rats were euthanized, separate tissues of heart, liver, lung, kidney, brain, spleen, stomach and testis were collected as soon as possible and then placed in PBS at $4{ }^{\circ} \mathrm{C}$ before washed and grinded in ice-cold RIPA lysis buffer by using the glass homogenizer. The lysates were then centrifuged and the supernatants were assayed for protein content. About $50 \mu \mathrm{g}$ of proteins were fractionated on $10 \%$ polyacrylamide gel and transferred onto PVDF membrane from Millipore Corporation (Billerica, MA, USA). 50mM Tris- $\mathrm{HCl}$ ( $\mathrm{pH} 7.5$ ) buffer, $150 \mathrm{mM} \mathrm{NaCl}$ and $0.1 \%$ Tween 20 ( (TBS-T)) containing 5\% non-fat dry milk to block the nonspecific binding sites of the membrane for $1 \mathrm{~h}$ at RT and incubated with primary anti-FH antibody (Abcam, USA) diluted in blocking buffer overnight at $4^{\circ} \mathrm{C}$.
Membranes were incubated with the respective horseradish peroxidase-labelled secondary antibody for $1 \mathrm{~h}$ at RT. Then the proteins were revealed using a Pierce ECL kit (Thermo Scientific, USA) following the manufacturer's instructions and visualized by ChemiDoc $\mathrm{XRS}^{+}$system (Bio-rad, USA).

\section{Immunofluorescence microscopy}

The primary fibroblast cells were obtained from the newborn rats as described above and plated on poly-Llysine coated coverslip, washed with PBS twice, fixed in $4 \%$ paraformaldehyde in PBS for 30 minutes and permeabilized in $0.1 \%$ Triton X-100 in PBS for 5 minutes at RT. Nonspecific binding sites were blocked with 5\% BSA in PBS (incubation buffer) for 30 minutes and the primary $\mathrm{FH}$ antibody was incubated overnight at $4^{\circ} \mathrm{C}$. On the following day after extensive washings with PBS, the corresponding secondary FITC-labelled antibody was added and incubated with the cells for $1 \mathrm{~h}$. Cells were then washed and stained with Hoechst33342 for nuclear visualisation. Confocal images were then obtained using the microscope Olympus FV1200 (Olympus, Japan).

\section{Laboratory blood examinations}

Rats were anesthetized with $10 \%$ chloral hydrate after having fasted overnight and the blood samples were obtained from the abdominal aorta before euthanized. 
Table 4: Results of hematology, blood chemistry

\begin{tabular}{|c|c|c|c|c|c|c|}
\hline \multirow[b]{2}{*}{ Test } & \multicolumn{3}{|c|}{ WT } & \multicolumn{3}{|c|}{ KO } \\
\hline & $\begin{array}{l}\text { Total } \\
(n=6)\end{array}$ & $\begin{array}{l}\text { Male } \\
(n=3)\end{array}$ & $\begin{array}{l}\text { female } \\
(n=3)\end{array}$ & $\begin{array}{l}\text { Total } \\
(n=6)\end{array}$ & $\begin{array}{l}\text { Male } \\
(n=3)\end{array}$ & $\begin{array}{c}\text { female } \\
(n=3)\end{array}$ \\
\hline \multicolumn{7}{|l|}{ Hematology } \\
\hline White blood cells $\left(\times 10^{9} / \mathrm{L}\right)$ & $6.1 \pm 1.2$ & $6.5 \pm 1.4$ & $5.7 \pm 1.1$ & $3.1 \pm 0.6^{* *}$ & $3.2 \pm 0.9 *$ & $3.0 \pm 0.4 * *$ \\
\hline Red blood cells $\left(\times 10^{12} / \mathrm{L}\right)$ & $7.9 \pm 0.9$ & $8.6 \pm 0.2$ & $7.2 \pm 0.8$ & $8.5 \pm 0.5$ & $8.9 \pm 0.3$ & $8.1 \pm 0.3$ \\
\hline Haemoglobin $(\mathrm{g} / \mathrm{L})$ & $139.0 \pm 11.7$ & $146.0 \pm 5.0$ & $132.0 \pm 13.1$ & $143.9 \pm 6.0$ & $145.0 \pm 7$ & $145.0 \pm 7$ \\
\hline Hematocrit $(\%)$ & $41.7 \pm 3.0$ & $43.4 \pm 1.6$ & $39.9 \pm 3.3$ & $41.9 \pm 1.5$ & $42.1 \pm 1.6$ & $41.7 \pm 1.6$ \\
\hline Platelets $\left(\times 10^{9} / \mathrm{L}\right)$ & $1129.3 \pm 150.4$ & $1106.3 \pm 112.2$ & $1152.3 \pm 205.8$ & $981.3 \pm 113.0$ & $1004.0 \pm 139.6$ & $964.3 \pm 107.8$ \\
\hline Mean platelet volume (\%) & $8.6 \pm 0.2$ & $8.7 \pm 0.3$ & $8.5 \pm 0.2$ & $8.4 \pm 0.5$ & $8.1 \pm 0.5$ & $8.7 \pm 0.4$ \\
\hline Platelet hematocrit (fL) & $1.0 \pm 0.1$ & $1.0 \pm 0.1$ & $1.0 \pm 0.2$ & $0.8 \pm 0.1^{*}$ & $0.8 \pm 0.1^{*}$ & $0.8 \pm 0.1$ \\
\hline Mean corpusular volume (fL) & $52.9 \pm 3.6$ & $50.3 \pm 0.9$ & $55.6 \pm 3.4$ & $49.6 \pm 2.5$ & $47.2 \pm 1.4$ & $51.4 \pm 1.1$ \\
\hline Mean corpusular hemoglobin (pg) & $17.6 \pm 1.0$ & $16.9 \pm 0.3$ & $18.3 \pm 0.8$ & $17.1 \pm 0.9$ & $16.2 \pm 0.5$ & $17.7 \pm 0.4$ \\
\hline $\begin{array}{l}\text { Mean corpusular hemoglobin } \\
\text { concerntration }(\mathrm{g} / \mathrm{L})\end{array}$ & $333.5 \pm 5.8$ & $336.7 \pm 0.6$ & $330.3 \pm 7.3$ & $343.7 \pm 2.9$ & $344.3 \pm 4.1$ & $343.3 \pm 2.2$ \\
\hline Neutral (\%) & Not detected & Not detected & Not detected & Not detected & Not detected & Not detected \\
\hline Lymphocyte (\%) & $57.8 \pm 6.3$ & $58.5 \pm 5.9$ & $57.1 \pm 7.9$ & $54.8 \pm 7.8$ & $50.7 \pm 7.0$ & $57.8 \pm 7.9$ \\
\hline Mononucleosis (\%) & $4.6 \pm 0.6$ & $4.6 \pm 0.1$ & $4.5 \pm 0.9$ & $3.4 \pm 0.7^{*}$ & $3.3 \pm 0.7^{*}$ & $3.6 \pm 0.8^{* *}$ \\
\hline Eosimophil (\%) & $1.6 \pm 0.8$ & $1.0 \pm 0.2$ & $2.1 \pm 0.9$ & $1.0 \pm 0.8$ & $1.0 \pm 0.9$ & $1.0 \pm 0.1$ \\
\hline Basophilic leukemia (\%) & Not detected & Not detected & Not detected & Not detected & Not detected & Not detected \\
\hline Neutrophil (\#) & Not detected & Not detected & Not detected & Not detected & Not detected & Not detected \\
\hline Lymphocyte absolute value (\#) & $3.6 \pm 1.1$ & $3.8 \pm 1.0$ & $3.3 \pm 1.3$ & $1.7 \pm 0.6^{* *}$ & $1.7 \pm 0.9 *$ & $1.8 \pm 0.5^{* *}$ \\
\hline Mononucleosis (\#) & $0.3 \pm 0.1$ & $0.3 \pm 0.2$ & $0.3 \pm 0.1$ & $0.2 \pm 0.3$ & $0.4 \pm 0.5$ & $0.1 \pm 0.0$ \\
\hline Eosimophil (\#) & $0.09 \pm 0.03$ & $0.06 \pm 0.01$ & $0.1 \pm 0.0$ & $0.04 \pm 0.04 *$ & $0.04 \pm 0.06$ & $0.03 \pm 0.00 * * *$ \\
\hline Basophilic leukemia (\#) & Not detected & Not detected & Not detected & Not detected & Not detected & Not detected \\
\hline $\begin{array}{l}\text { Red blood cell volume distribution } \\
\text { width standard deviation (\%) }\end{array}$ & $25.8 \pm 1.9$ & $25.5 \pm 0.5$ & $26.1 \pm 2.9$ & $26.8 \pm 1.7$ & $28.0 \pm 1.7$ & $25.6 \pm 1.2$ \\
\hline $\begin{array}{l}\text { Red blood cell volume distribution } \\
\text { width coefficient of variation }(\%)\end{array}$ & $16.0 \pm 2.6$ & $17.3 \pm 0.7$ & $14.6 \pm 3.3$ & $17.5 \pm 2.3$ & $19.6 \pm 1.4$ & $16.0 \pm 1.2$ \\
\hline Platelet distribution width (fL) & $9.6 \pm 0.6$ & $9.8 \pm 0.7$ & $9.5 \pm 0.5$ & $9.4 \pm 0.9$ & $8.9 \pm 1.0$ & $9.8 \pm 0.7$ \\
\hline Platelet larger cell ratio (\%) & $15.7 \pm 2.0$ & $16.5 \pm 2.5$ & $14.8 \pm 1.5$ & $14.3 \pm 3.8$ & $11.7 \pm 3.8$ & $16.1 \pm 2.8$ \\
\hline \multicolumn{7}{|l|}{ Blood chemistry variables } \\
\hline Alanine amio transferase (IU/L) & $41.8 \pm 6.6$ & $47.3 \pm 3.1$ & $36.3 \pm 3.2$ & $30.4 \pm 19.2$ & $43.7 \pm 5.7$ & $35.8 \pm 11.5$ \\
\hline Aspartate amino transferase (IU/L) & $122.5 \pm 14.0$ & $130.3 \pm 10.1$ & $114.7 \pm 14.4$ & $86.1 \pm 50.6$ & $124.3 \pm 9.7$ & $100.5 \pm 9.8$ \\
\hline$\gamma$-Glutamyl transpeptadase (IU/L) & $1.2 \pm 0.4$ & $1.3 \pm 0.6$ & $1.0 \pm 0.0$ & $1.2 \pm 0.8$ & $1.3 \pm 0.6$ & $1.8 \pm 0.5$ \\
\hline Alkaline phosphatase (IU/L) & $60.3 \pm 34.1$ & $84.7 \pm 31.0$ & $36.0 \pm 13.1$ & $40.0 \pm 27.6$ & $69.3 \pm 4.5$ & $38.0 \pm 9.4$ \\
\hline Total bilirubin (umol/L) & $-0.2 \pm 0.1$ & $-0.2 \pm 0.1$ & $-0.2 \pm 0.1$ & $-0.03 \pm 0.36$ & $-0.3 \pm 0.3$ & $0.2 \pm 0.4$ \\
\hline Direct bilirubin (umol/L) & $0.3 \pm 0.1$ & $0.2 \pm 0.1$ & $0.4 \pm 0.2$ & $0.2 \pm 0.2$ & $0.3 \pm 0.2$ & $0.4 \pm 0.2$ \\
\hline Indirect bilirubin (umol/L) & $0.3 \pm 0.2$ & $0.4 \pm 0.1$ & $0.1 \pm 0.2$ & $-0.3 \pm 0.3$ & $-0.6 \pm 0.2$ & $-0.2 \pm 0.3$ \\
\hline Total protein $(\mathrm{g} / \mathrm{L})$ & $64.8 \pm 6.4$ & $64.4 \pm 1.6$ & $65.1 \pm 9.9$ & $51.4 \pm 29.3$ & $64.0 \pm 1.3$ & $67.7 \pm 2.9$ \\
\hline Albumin $(g / L)$ & $34.5 \pm 3.0$ & $33.5 \pm 1.7$ & $35.5 \pm 4.1$ & $27.9 \pm 15.9$ & $33.9 \pm 0.9$ & $37.3 \pm 2.2$ \\
\hline Globulin $(\mathrm{g} / \mathrm{L})$ & $30.3 \pm 3.9$ & $31.0 \pm 0.2$ & $29.6 \pm 6.0$ & $23.6 \pm 13.4$ & $30.1 \pm 1.1$ & $30.5 \pm 0.8$ \\
\hline Glucose $(\mathrm{mmol} / \mathrm{L})$ & $7.3 \pm 1.3$ & $8.2 \pm 0.3$ & $6.4 \pm 1.4$ & $5.1 \pm 3.0$ & $7.2 \pm 0.4$ & $6.0 \pm 1.2$ \\
\hline Blood urea nitrogen $(\mathrm{mmol} / \mathrm{L})$ & $7.3 \pm 0.7$ & $7.8 \pm 0.5$ & $6.7 \pm 0.3$ & $8.7 \pm 1.0^{*}$ & $8.1 \pm 0.5$ & $9.2 \pm 1.0^{*}$ \\
\hline Uric acid (umol/L) & $162.8 \pm 81.0$ & $202.0 \pm 12.5$ & $123.7 \pm 107.9$ & $146.6 \pm 12.3 *$ & $153.7 \pm 11.9^{* *}$ & $141.3 \pm 10.9 *$ \\
\hline Serum creatinine (IU/L) & $886.2 \pm 413.7$ & $1094.3 \pm 524.4$ & $678.0 \pm 150.9$ & $\begin{array}{l}1014.7 \pm \\
581.6^{*}\end{array}$ & $1238.7 \pm 170.2^{*}$ & $\begin{array}{l}846.8 \pm \\
754.6^{* *}\end{array}$ \\
\hline Creatine kinase isoenzymes-MB (IU/L) & $35.8 \pm 5.2$ & $36.7 \pm 7.6$ & $35.0 \pm 2.6$ & $37.3 \pm 5.3$ & $41.0 \pm 1.0$ & $34.5 \pm 5.6$ \\
\hline Creatinine (umol/L) & $57.2 \pm 2.9$ & $55.5 \pm 1.7$ & $59.3 \pm 2.1$ & $64.4 \pm 4.2$ & $60.7 \pm 2.9$ & $67.3 \pm 2.1$ \\
\hline
\end{tabular}

Where appropriate, data are presented as the mean \pm the standard deviation.

${ }^{*} P<0.05$ (paired $t$-test) vs WT, ${ }^{* *} P<0.01$ (paired $t$-test) vs WT, ${ }^{* * *} P<0.001$ (paired $t$-test) vs WT. 
Blood samples were collected with uncoated, EDTA and citrate-coated tubes, and the hematologic parameters were analysed with Siemens Advia 2120 (Siemens, USA) for the following cuntings/measurements: white blood cell (WBC), red blood cell (RBC), haemoglobin (HGB), hematocrit (HCT), platelet count (PLT), mean platelet volume (MPV), platelet hematocrit (PCT), mean corpusular volume (MCV), mean corpusular hemoglobin $(\mathrm{MCH})$, mean corpusular hemoglobin concerntration (MCHC), \%neutral (\%NEUT), \%lymphocyte (\%LYMPH), $\%$ mononucleosis (\%MONO), \%eosimophil (\%EOS), \%basophilic leukemia (\%BASO), \#neutrophil (\#NEUT), \#lymphocyte (\#LYMPH), \#mononucleosis (\#MONO), \#eosimophil (\#EOS), \#basophilic leukemia (\#BASO), red blood cell volume distribution width standard deviation (RDW-SD), red blood cell volume distribution width coefficient of variation (RDW-CV), platelet distribution width (PDW) and platelet larger cell ratio (P-LCR). Additional, blood tests were performed with a Synchron Cx 5 clinical system Beckman Coulter (USA) for the followings: alanine amio transferase (ALT), aspartate amino transferase (AST), $\gamma$-glutamyl transpeptadase (GGT), alkaline phosphatase (ALP), total bilirubin (TBIL), direct bilirubin (DBIL), indirect bilirubin (IBIL), total protein (TP), albumin (ALB), globulin (GLB), glucose (GLU), blood urea nitrogen (BUN), uric acid (UA), creatinine (CRE), cardiac Marker (CK) and creatine kinase isoenzymes (CK-MB). Furthermore, blood smears were prepared and stained with the Wright method in order to detect the morphology of the cells.

\section{Histological evaluation}

Rats were euthanized with chloral hydrate at the end of the experiment and the kidneys were collected for histological sample preparation. Formalin-fixed paraffinembedded tissue sections were cut and stained with Harris hematoxylin (Sigma-Aldrich, USA) and eosin solution (Sigma-Aldrich, USA). Briefly, slides were deparaffinized in deionized water and then stained with hematoxylin for 3 minutes, rinsed under running tap water, $70 \%$ ethanol and then stained with eosin for 3 minutes before the slides were rinsed and dehydrated in ethanol, cleared in xylene, and then mounted by machine (Dako, Denmark). The slides were histologically evaluated under an optical double-headed microscope (Olympus, Tokyo, Japan).

\section{Immunohistochemistry (IHC)}

The paraffin-embedded tissues were cut to 3- $\mu \mathrm{m}$ sections. Dako Envision FLEX+ system (K8012; Dako, Glostrup, Denmark) was used to deparaffinized and epitopes were unmasked in PT link with low $\mathrm{pH}$ target retrieval solution (Dako, Denmark). Briefly, the slides were blocked for 5 minutes with peroxidase blocking solution (Dako) at room temperature (RT), and then incubated with rabbit polyclonal Ki67 antibody (cat. no. ab15580; 1:800;
Abcam, USA), rabbit polyclonal p53 antibody (cat. no. ab131442; 1:500; Abcam, USA) and rabbit polyclonal sox9 antibody (cat. no. ab26414; 1:1000; Abcam, USA) at $4^{\circ} \mathrm{C}$ overnight before incubated with rabbit linker (Dako, Denmark) for 15 minutes, horseradish peroxidase (Dako) for 30 minutes at RT. The slides were subsequently stained with 3,3'-diaminobenzidine tetrahydrochloride for 10 minutes, counter-stained with hematoxylin, dehydrated, and mounted in Richard-Allan Scientific Cytoseal XYL (Thermo Fisher Scientific, Waltham, MA, USA) before evaluated under an optical double-headed microscope (Olympus, Tokyo, Japan).

\section{Statistics}

All values are expressed as mean $\pm \mathrm{SD}$, and the student $t$-test was used to evaluate the significance differences between the two groups. The significance level was set as $P<0.05$.

\section{ACKNOWLEDGMENTS AND FUNDING}

This study was financially supported by National Natural Science Foundation of China (81272824).

\section{CONFLICTS OF INTEREST}

All authors declare that they have no conflicts of interests to state.

\section{REFERENCES}

1. Rolstad B. The early days of NK cells: an example of how a phenomenon led to detection of a novel immune receptor system - lessons from a rat model. Front Immunol. 2014; $5: 283$.

2. Steiner MA, Sciarretta C, Pasquali A, Jenck F. The selective orexin receptor 1 antagonist ACT-335827 in a rat model of diet-induced obesity associated with metabolic syndrome. Front Pharmacol. 2013; 4:165.

3. Irving AA, Yoshimi K, Hart ML, Parker T, Clipson L, Ford MR, Kuramoto T, Dove WF, Amos-Landgraf JM. The utility of Apc-mutant rats in modeling human colon cancer. Dis Model Mech. 2014; 7:1215-1225.

4. Le Provost F, Lillico S, Passet B, Young R, Whitelaw B, Vilotte JL. Zinc finger nuclease technology heralds a new era in mammalian transgenesis. Trends Biotechnol. 2010; 28:134-141.

5. Sun N, Zhao H. Transcription activator-like effector nucleases (TALENs): a highly efficient and versatile tool for genome editing. Biotechnology and bioengineering. 2013; 110:1811-1821.

6. Hartenian E, Doench JG. Genetic screens and functional genomics using CRISPR/Cas9 technology. FEBS J. 2015; 282:1383-1393. 
7. Mann ML, Ezzati M, Tarnawa ED, Carr BR. Fumarate Hydratase Mutation in a Young Woman With Uterine Leiomyomas and a Family History of Renal Cell Cancer. Obstet Gynecol. 2015; 126:90-92.

8. Yoshinaga Y, Nakai H, Hayashi R, Ito A, Kariya N, Ito M, Shimomura Y. Novel splice site mutation in the fumarate hydratase $(\mathrm{FH})$ gene is associated with multiple cutaneous leiomyomas in a Japanese patient. J Dermatol. 2015.

9. Perrier-Trudova V, Huimin BW, Kongpetch S, Huang D, Ong P, A LEF, Poon SL, Siew EY, Myint SS, Gad S, Gardie B, Couve S, Foong YM, et al. Fumarate Hydratasedeficient Cell Line NCCFH1 as a New In Vitro Model of Hereditary Papillary Renal Cell Carcinoma Type 2. Anticancer Res. 2015; 35:6639-6653.

10. Picaud S, Kavanagh KL, Yue WW, Lee WH, Muller-Knapp S, Gileadi O, Sacchettini J, Oppermann U. Structural basis of fumarate hydratase deficiency. J Inherit Metab Dis. 2011; 34:671-676.

11. Carlson-Stevermer J, Goedland M, Steyer B, Movaghar A, Lou M, Kohlenberg L, Prestil R, Saha K. High-Content Analysis of CRISPR-Cas9 Gene-Edited Human Embryonic Stem Cells. Stem cell reports. 2016; 6:109-120.

12. Cheng AW, Jillette N, Lee P, Plaskon D, Fujiwara Y, Wang W, Taghbalout A, Wang H. Casilio: a versatile CRISPR-Cas9-Pumilio hybrid for gene regulation and genomic labeling. Cell Res. 2016.

13. Kalebic N, Taverna E, Tavano S, Wong FK, Suchold D, Winkler S, Huttner WB, Sarov M. CRISPR/Cas9-induced disruption of gene expression in mouse embryonic brain and single neural stem cells in vivo. EMBO Rep. 2016.

14. Linehan WM, Rouault TA. Molecular pathways: Fumarate hydratase-deficient kidney cancer--targeting the Warburg effect in cancer. Clin Cancer Res. 2013; 19:3345-3352.

15. Reyes C, Karamurzin Y, Frizzell N, Garg K, Nonaka D, Chen YB, Soslow RA. Uterine smooth muscle tumors with features suggesting fumarate hydratase aberration: detailed morphologic analysis and correlation with S- (2-succino)cysteine immunohistochemistry. Mod Pathol. 2014; 27:1020-1027.

16. Smith S, Casady M, Driscoll MS. Novel mutation in the fumarate hydratase gene in a patient with Reed syndrome. Dermatol Online J. 2015; 21.

17. Llamas-Velasco M, Requena L, Kutzner H, Scharer L, Rutten A, Hantschke M, Paredes BE, Mentzel T. Fumarate hydratase immunohistochemical staining may help to identify patients with multiple cutaneous and uterine leiomyomatosis (MCUL) and hereditary leiomyomatosis and renal cell cancer (HLRCC) syndrome. J Cutan Pathol. 2014; 41:859-865.

18. Wheeler KC, Warr DJ, Warsetsky SI, Barmat LI. Novel fumarate hydratase mutation in a family with atypical uterine leiomyomas and hereditary leiomyomatosis and renal cell cancer. Fertil Steril. 2016; 105:144-148.
19. Pollard PJ, Spencer-Dene B, Shukla D, Howarth K, Nye E, El-Bahrawy M, Deheragoda M, Joannou M, McDonald S, Martin A, Igarashi P, Varsani-Brown S, Rosewell I, et al. Targeted inactivation of fhl causes proliferative renal cyst development and activation of the hypoxia pathway. Cancer cell. 2007; 11:311-319.

20. Frezza C, Pollard PJ, Gottlieb E. Inborn and acquired metabolic defects in cancer. J Mol Med (Berl). 2011; 89:213-220.

21. Frezza C, Zheng L, Folger O, Rajagopalan KN, MacKenzie ED, Jerby L, Micaroni M, Chaneton B, Adam J, Hedley A, Kalna G, Tomlinson IP, Pollard PJ, et al. Haem oxygenase is synthetically lethal with the tumour suppressor fumarate hydratase. Nature. 2011; 477:225-228.

22. Sourbier C, Ricketts CJ, Matsumoto S, Crooks DR, Liao PJ, Mannes PZ, Yang Y, Wei MH, Srivastava G, Ghosh S, Chen V, Vocke CD, Merino M, et al. Targeting ABL1mediated oxidative stress adaptation in fumarate hydratasedeficient cancer. Cancer cell. 2014; 26:840-850.

23. Cakir M, Polat A, Tekin S, Vardi N, Taslidere E, Rumeysa Duran Z, Tanbek K. The effect of dexmedetomidine against oxidative and tubular damage induced by renal ischemia reperfusion in rats. Ren Fail. 2015; 37:704-708.

24. Ooi A, Furge KA. Fumarate hydratase inactivation in renal tumors: HIF1alpha, NRF2, and "cryptic targets" of transcription factors. Chin J Cancer. 2012; 31:413-420.

25. Kaelin WG, Jr. DisABLing kidney cancers caused by fumarate hydratase mutations. Cancer cell. 2014; 26:779-780.

26. Llamas-Velasco M, Requena L, Adam J, Frizzell N, Hartmann A, Mentzel T. Loss of Fumarate Hydratase and Aberrant Protein Succination Detected With S- (2-Succino)Cysteine Staining to Identify Patients With Multiple Cutaneous and Uterine Leiomyomatosis and Hereditary Leiomyomatosis and Renal Cell Cancer Syndrome. Am J Dermatopathol. 2016.

27. Buelow B, Cohen J, Nagymanyoki Z, Frizzell N, Joseph NM, McCalmont T, Garg K. Immunohistochemistry for 2-Succinocysteine (2SC) and Fumarate Hydratase (FH) in Cutaneous Leiomyomas May Aid in Identification of Patients With HLRCC (Hereditary Leiomyomatosis and Renal Cell Carcinoma Syndrome). Am J Surg Pathol. 2016.

28. Trpkov K, Hes O, Agaimy A, Bonert M, Martinek P, Magi-Galluzzi C, Kristiansen G, Luders C, Nesi G, ComperatE, Sibony M, Berney DM, Mehra R, et al. Fumarate Hydratasedeficient Renal Cell Carcinoma Is Strongly Correlated With Fumarate Hydratase Mutation and Hereditary Leiomyomatosis and Renal Cell Carcinoma Syndrome. Am J Surg Pathol. 2016.

29. Habib SL, Liang S. Hyperactivation of Akt/mTOR and deficiency in tuberin increased the oxidative DNA damage in kidney cancer patients with diabetes. Oncotarget. 2014; 5:2542-2550. doi: 10.18632/oncotarget.1833.

30. Zhu J, Sammons MA, Donahue G, Dou Z, Vedadi M, Getlik M, Barsyte-Lovejoy D, Al-awar R, Katona BW, 
Shilatifard A, Huang J, Hua X, Arrowsmith CH, et al. Gainof-function $\mathrm{p} 53$ mutants co-opt chromatin pathways to drive cancer growth. Nature. 2015; 525:206-211.

31. Larsimont JC, Youssef KK, Sanchez-Danes A, Sukumaran V, Defrance M, Delatte B, Liagre M, Baatsen P, Marine JC, Lippens S, Guerin C, Del Marmol V, Vanderwinden JM, et al. Sox9 Controls Self-Renewal of Oncogene Targeted Cells and Links Tumor Initiation and Invasion. Cell stem cell. 2015; 17:60-73.

32. Doyle EL, Booher NJ, Standage DS, Voytas DF, Brendel VP, Vandyk JK, Bogdanove AJ. TAL Effector-Nucleotide Targeter (TALE-NT) 2.0: tools for TAL effector design and target prediction. Nucleic Acids Res. 2012; 40:W117-122.
33. Shaukat I, Barre L, Venkatesan N, Li D, Jaquinet JC, Fournel-Gigleux S, Ouzzine M. Targeting of Proteoglycan Synthesis Pathway: A New Strategy to Counteract Excessive Matrix Proteoglycan Deposition and Transforming Growth Factor-beta1-Induced Fibrotic Phenotype in Lung Fibroblasts. PloS one. 2016; 11:e0146499.

34. Ahn JK, Kim S, Hwang J, Kim J, Lee YS, Koh EM, Kim KH, Cha HS. Metabolomic Elucidation of the Effects of Curcumin on Fibroblast-Like Synoviocytes in Rheumatoid Arthritis. PloS one. 2015; 10:e145539. 